LA-UR-03 0911

Approved for public release; distribution is unlimited.
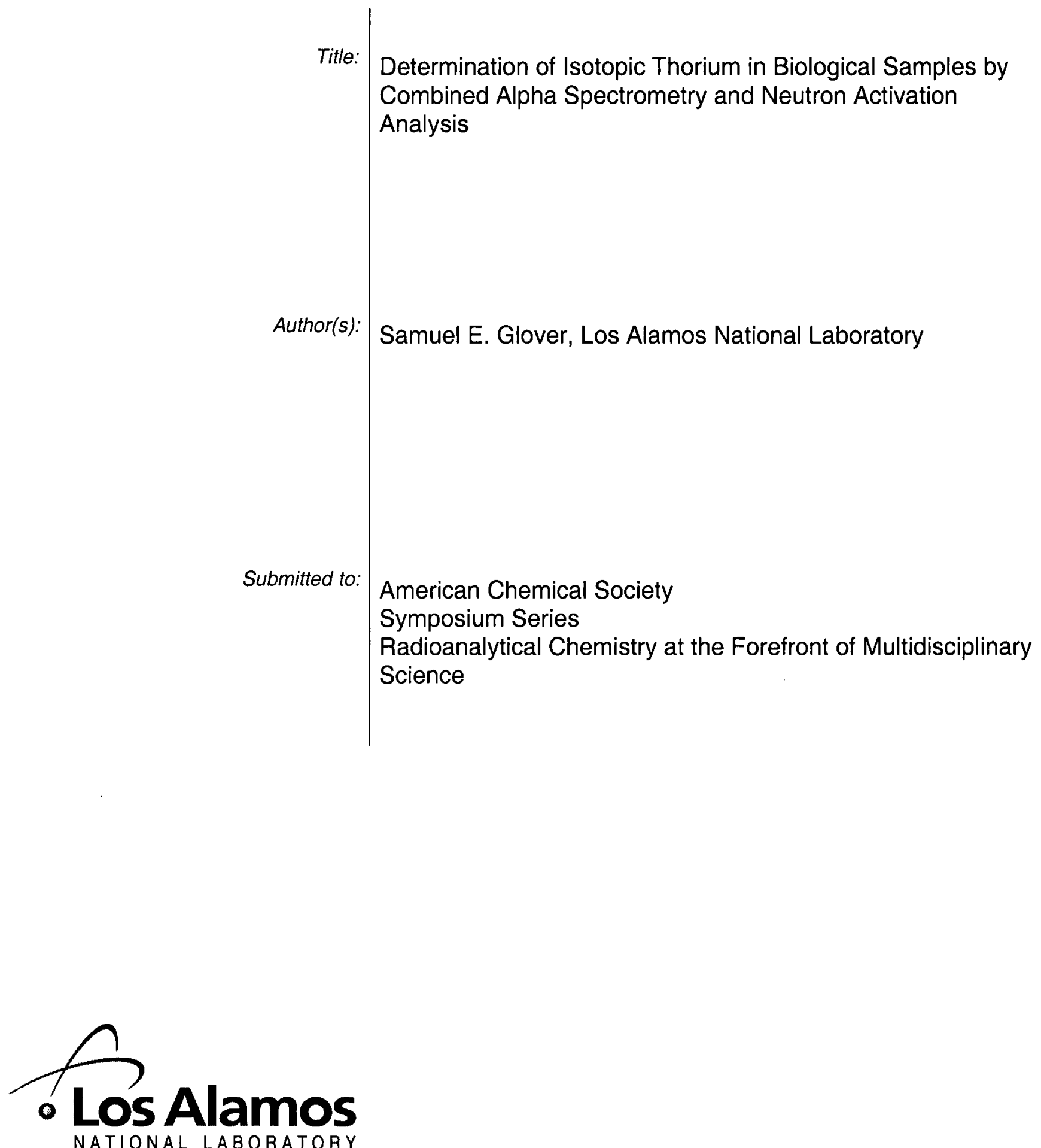

Los Alamos National Laboratory, an affirmative action/equal opportunity employer, is operated by the University of California for the U.S. Department of Energy under contract W-7405-ENG-36. By acceptance of this article, the publisher recognizes that the U.S. Government retains a nonexclusive, royalty-free license to publish or reproduce the published form of this contribution, or to allow others to do so, for U.S. Government purposes. Los Alamos National Laboratory requests that the publisher identify this article as work performed under the auspices of the U.S. Department of Energy. Los Alamos National Laboratory strongly supports academic freedom and a researcher's right to publish; as an institution, however, the Laboratory does not endorse the viewpoint of a publication or guarantee its technical correctness. 


\title{
Chapter
}

\section{DETERMINATION OF ISOTOPIC THORIUM IN BIOLOGICAL SAMPLES BY COMBINED ALPHA SPECTROMETRY AND NEUTRON ACTIVATION} ANALYSIS

\author{
S.E. Glover \\ Isotope and Nuclear Chemistry, Los Alamos National Laboratory
}

Thorium is a naturally occurring element for whom all isotopes are radioactive. Many of these isotopes are alpha emitting radionuclides, some of which have limits for inhalation lower than plutonium in current regulations. Neutron activation analysis can provide for the low-level determination of ${ }^{232} \mathrm{Th}$ but can not determine other isotopes of dosimetric importance. Biological and environmental samples often have large quantities of materials which activate strongly, limiting the capabilities of instrumental neutron activiation analysis. This paper will discuss the application of a combined technique using alpha spectrometry and radiochemical neutron activiation analysis for the determination of isotopic thorium. 


\section{Introduction}

A number of radiometric and non-radiometric methods have been used for the determination of ${ }^{232} \mathrm{Th}$ in biological and environmental samples. These include alpha spectrometry ${ }^{1.2}$, gamma ray spectrometry, ${ }^{3}$ instrumental neutron activation analysis (INAA), ${ }^{3}$ radiochemical neutron activation analysis (RNAA), ${ }^{4,5,6,7,8,9}$ pre-concentration neutron activation analysis (PCNAA), ${ }^{10}$ absorption spectroscopy, ${ }^{6}$ and inductively coupled plasma mass spectrometry (ICP-MS). ${ }^{11,12,13,14}$ However, only alpha spectrometry following radiochemical separation allows the determination of the thorium isotopes with the greatest dosimetric impact for biological samples, ${ }^{228} \mathrm{Th},{ }^{230} \mathrm{Th}$, and ${ }^{232} \mathrm{Th}$. Alpha spectrometry also allows the use of a tracer (e.g. ${ }^{229} \mathrm{Th}$ or ${ }^{234} \mathrm{Th}$ ) for chemical yield determination. ${ }^{1}$ While alpha spectrometry offers good radiometric detection limits $\left(2.8 \times 10^{-4} \mathrm{~Bq} / \mathrm{sample}\right)^{2}$, the very long half-life of ${ }^{232} \mathrm{Th}\left(4.5 \times 10^{9}\right.$ years) makes the mass detection limit fairly high $(-70 \mathrm{ng})$ compared to isotopes with shorter half-lives.

Studies of human populations by a number of investigators have provided some information on the distribution of thorium in the human body as the result of long-term chronic intake from environmental sources of thorium (i.e. nonoccupational intake). All of these studies indicate that the skeleton is the major deposition site for thorium for persons exposed principally through inhalation as well as for persons exposed to environmental sources of thorium (presumably, mostly through inhalation). However, these studies on human exposure were based on the measurement of only a few samples from each body and in many cases the analytical results were of low precision because of the very low activities of thorium isotopes in human tissues from normal individuals.

Neutron activation analysis has long been used for the determination of ${ }^{232} \mathrm{Th}$ via the $(\mathrm{n}, \gamma)$ reaction and subsequent beta decay of the short lived ${ }^{233} \mathrm{Th}$ $\left(\mathrm{t}_{1 / 2}=22.3 \mathrm{~min}\right){ }^{15}$ product to ${ }^{233} \mathrm{~Pa}\left(\mathrm{t}_{1 / 2}=27.0 \text { days }\right)^{15}$. ${ }^{232} \mathrm{Th}$ has large $(\mathrm{n}, \gamma)$ crosssections $\left(\sigma_{\gamma}=7.37 \mathrm{~b}, \mathrm{I}=85 \mathrm{~b}\right)^{16}$ and ${ }^{233} \mathrm{~Pa}$ is determined by measuring the 300 $(6.2 \%), 312(36 \%)$ or $340(4.2 \%) \mathrm{keV}$ gamma rays ${ }^{\prime 5}$. In radiochemical neutron activation analysis (RNAA) for the determination of ${ }^{232} \mathrm{Th},{ }^{233} \mathrm{~Pa}$ is separated from matrix elements following neutron activation to minimize interferences and reduce the gamma-ray background. While this technique is capable of much lower detection limits for ${ }^{232} \mathrm{Th}$ compared to alpha spectrometry, RNAA is not suitable for isotopic thorium analysis.

Neutron activation analysis is a multielement technique capable of low detection limits, good precision, and in some applications, can have essentially a zero blank. However, in some instances, it is helpful to use various preconcentration methods to allow the use of larger samples or to remove specific interferences. These techniques, known as pre-concentration neutron activation analysis, PCNAA, have many of the same advantages of NAA but may have 
contribution to the blank by reagents and environmental factors which must be assessed. This paper will present one such work for the determination of isotopic thorium combining alpha spectrometry, PCNAA, and PCRNAA.

\section{Experimental}

\section{Preparation of reagents and irradiation vials.}

A thorium standard ${ }^{232} \mathrm{Th}$ ) for neutron activation analysis was prepared by dissolving $\mathrm{Th}\left(\mathrm{NO}_{3}\right)_{4} \bullet \mathrm{xH}_{2} \mathrm{O}$ (Johnson, Matthey, \& Co.) in $1 \mathrm{M} \mathrm{HNO}_{3}$ and the isotopic concentration $\left({ }^{228} \mathrm{Th},{ }^{230} \mathrm{Th},{ }^{232} \mathrm{Th}\right)$ determined by alpha spectrometry. The ${ }^{229} \mathrm{Th}$ tracer used for the determination of isotopic thorium was prepared from the National Institute for Standards and Technology (NIST) Standard Reference Material (SRM 4328A). ${ }^{231} \mathrm{~Pa}$ was prepared from Amersham Certified Reference Materia PNP10010l. Working solutions were prepared by volumetric dilution of a known weight of reference material to an appropriate working concentration $(\sim 0.2 \mathrm{~Bq} / \mathrm{mL})$.

All reagents $\left(\mathrm{HNO}_{3}, \mathrm{HCl}\right)$ were trace metal grade (Fisher Scientific). Deionized water was used for the preparation of all solutions and was prepared to $18 \mathrm{M} \Omega$ using distilled water in a Nanopure ${ }^{\mathrm{TM}}$ system.

Flip-top polyethylene vials (Fisher scientific) were soaked for $24 \mathrm{hr}$ in $40 \%$ $\mathrm{HNO}_{3}(\mathrm{v} / \mathrm{v})$, rinsed with de-ionized water 2-3 times, and then soaked for $24 \mathrm{hr}$ in de-ionized water. The vials were drained, soaked in acetone for $24 \mathrm{hr}$, and then dried in a laminar flow hood.

Electrodeposition disks were prepared from $0.25 \mathrm{~mm}$ thick sheets of $99.7 \%$ pure vanadium (Aldrich) machine punched to $5 / 8$ " diameter planchets. Disks were rinsed with acetone prior to use.

\section{Sample preparation}

Human tissue samples were dried at $110^{\circ} \mathrm{C}$, ashed to $450^{\circ} \mathrm{C}$ and then wet ashed with $\mathrm{HNO}_{3}$ and $\mathrm{H}_{2} \mathrm{O}_{2}{ }^{17}$ Residues from certain tissues (e.g. lung and lymph nodes) were treated with HF to dissolve silicates. Samples were then dissolved in $8 \mathrm{M} \mathrm{HCl}$ and an aliquot selected for analysis. Quality control samples consisting of an aliquot of diluted ${ }^{232} \mathrm{Th}$ standard (from the $\mathrm{Th}\left(\mathrm{NO}_{3}\right)_{4}$ stock solution) as well as a reagent blank were analyzed with each set of samples. The radiochemical recovery was determined by adding approximately $0.08 \mathrm{~Bq}$ $(5 \mathrm{dpm})$ of ${ }^{229} \mathrm{Th}$ tracer to each sample aliquot. 


\section{Radiochemical separation of thorium from samples}

The sample, quality control samples, and blanks were taken to dryness on a hot plate prior to separation and wet ashed repeatedly with concentrated $\mathrm{HNO}_{3}$ to ensure that the ${ }^{229} \mathrm{Th}$ tracer and thorium in the sample were in the same chemical form (i.e. Th(IV)) and thoroughly distributed within the sample. The aliquot, containing ${ }^{229} \mathrm{Th}$ tracer, was then dissolved in $8 \mathrm{M} \mathrm{HNO}_{3}$ and passed over $12 \mathrm{~cm}^{3}$ of $\mathrm{AG} 1 \times 8\left(\mathrm{Cl}^{-}\right.$form $)$that had been previously conditioned with 5 column volumes of $8 \mathrm{M} \mathrm{HNO}_{3}$. The columns were then rinsed with 5 column volumes of $8 \mathrm{M} \mathrm{HNO}_{3}$ and the thorium eluted with 5 column volumes of $9 \mathrm{M}$ $\mathrm{HCl}$ (to prevent co-elution of ${ }^{239} \mathrm{Pu}$ in the sample). Two $\mathrm{mL}$ of $0.36 \mathrm{M} \mathrm{NaHSO}_{4}$ were added to the eluent to prevent radiochemical losses during subsequent electrodeposition steps. The eluent was then taken to dryness and wet ashed with concentrated $\mathrm{HNO}_{3}$ and in some cases concentrated $\mathrm{H}_{2} \mathrm{SO}_{4}$ to destroy any organic material that was present following separation.

Samples were electroplated according to the method of Glover et al. ${ }^{18}$ Samples were dissolved in $5 \mathrm{~mL}$ of $0.75 \mathrm{M} \mathrm{H}_{2} \mathrm{SO}_{4}$, several drops of thymol blue indicator added, and then transferred into electrodeposition cells followed by two subsequent $3 \mathrm{~mL}$ rinses of $0.75 \mathrm{M} \mathrm{H}_{2} \mathrm{SO}_{4}$. The $\mathrm{pH}$ of the sample solution was adjusted to 1.5-2 using concentrated $\mathrm{NH}_{3}$. One important difference was the use of $99.7 \%$ pure vanadium planchets rather than stainless steel planchets typically used for electrodeposition.

\section{Determination of thorium by alpha spectrometry.}

After electrodeposition the ${ }^{228} \mathrm{Th},{ }^{230} \mathrm{Th},{ }^{232} \mathrm{Th}$, and the ${ }^{229} \mathrm{Th}$ tracer in each sample were determined by alpha spectrometry in a Canberra Alpha Analyst system equipped, with $450 \mathrm{~mm}^{2}$ detectors calibrated over the range of 3.5 to 7 $\mathrm{MeV}$ in 1024 channels. Samples were counted on the second shelf (approximately $0.5 \mathrm{~mm}$ source-to-detector distance) which yielded approximately a $20 \%$ efficiency (counts $/ \alpha$ emission). Detectors were energy calibrated using secondary sources of approximately $1 \mathrm{~Bq}$ each of ${ }^{234} \mathrm{U},{ }^{238} \mathrm{U}$, ${ }^{239} \mathrm{Pu}$, and ${ }^{241} \mathrm{Am}$. The detectors were efficiency calibrated using secondary sources containing approximately $15 \mathrm{~Bq}$ of ${ }^{242} \mathrm{Pu}$. These secondary sources were calibrated using NIST SRM $4906 \mathrm{~L}, \mathrm{a}{ }^{238} \mathrm{Pu}$ point source, at the greatest source-to-detector geometry $(\sim 4 \mathrm{~cm})$ to minimize geometry differences between the point source and the 5/8" planchet used for sample preparation. Background counts for each detector were of 300,000 seconds duration and samples were counted for 100,000 to 300,000 seconds. The chemical yield of the separation and electrodeposition steps was obtained by the ratio of the net counts of ${ }^{229} \mathrm{Th}$ versus the expected count rate of the decay corrected tracer. 


\section{Determination of ${ }^{232}$ Th by PCRNAA (ion exchange method)}

Samples were irradiated at the 1 MW TRIGA III fueled research reactor located at Washington State University for 6 hours with a thermal neutron flux of $6.5 \times 10^{13} \mathrm{~cm}^{-2} \mathrm{~s}^{-1}$. The samples were allowed to decay for approximately 12 hours in the pool to allow the short lived activation products to decay.

The vanadium planchets were dissolved using $10 \mathrm{~mL}$ of $8 \mathrm{M} \mathrm{HNO}_{3} / 0.025$ M HF spiked with approximately $0.2 \mathrm{~Bq}$ of ${ }^{231} \mathrm{~Pa}$ in a covered polyethylene beaker (Azlon ${ }^{\mathrm{TM}}$ ) suitable for heating to $130^{\circ} \mathrm{C}$. The addition of $\mathrm{HF}$ is required to keep the $\mathrm{Pa}$ in solution as it will rapidly hydrolyze. Also, this ensures the $\mathrm{Pa}$ was in chemical equilibrium with the ${ }^{231} \mathrm{~Pa}$ tracer which was also in $8 \mathrm{M}$ $\mathrm{HNO}_{3} / 0.025 \mathrm{M} \mathrm{HF}$. Following completion of this exothermic reaction, the beaker was heated at $90^{\circ} \mathrm{C}$ for 15 minutes to insure completion of the reaction. $90 \mathrm{~mL}$ of $9 \mathrm{M} \mathrm{HCl}$ were then added to the sample and allowed to cool to room temperature.

The ion exchange columns were prepared using a $10 \mathrm{~mL}$ Fast $\operatorname{Rad}^{\mathrm{TM}}$ polyethylene column (Environmental Express LTD) with $200 \mathrm{~mL}$ plastic reservoir containing $10 \mathrm{~mL}$ of Biorad AG $1 \times 8$ resin, $100-200$ mesh. The columns were washed with 5 column volumes of $0.5 \mathrm{M} \mathrm{HCl}$ to remove all actinides and pre-conditioned with 5 column volumes of $9 \mathrm{M} \mathrm{HCl}$ prior to addition of the samples. Glass components were not used for any step in these procedures due to the presense of HF in the samples.

Immediately prior to addition to the column, $2 \mathrm{~mL}$ of $0.5 \mathrm{M} \mathrm{Al}\left(\mathrm{NO}_{3}\right)_{3}$ was added to the sample to bind the flouride, the sample stirred thoroughly, and then added to the column. The beaker was rinsed three times with $9 \mathrm{M} \mathrm{HCl}$ and these rinses were also added to the column. Each step was allowed to pass completely through the column prior to addition of the next wash step. The column was washed with 5 column volumes of $9 \mathrm{M} \mathrm{HCl}$, then rinsed twice with 2.5 column volumes of $8 \mathrm{H} \mathrm{HNO}_{3}$. The $\mathrm{Pa}$ was then eluted with 10 column volumes of $9 \mathrm{M} \mathrm{HCl} / 0.025 \mathrm{M} \mathrm{HF}$ into a polyethylene beaker.

\section{Electrodeposition of $\mathrm{Pa}$}

It was quickly determined that a modification of the electrodeposition method would be required for completion of this work due to the HF used in the elution of $\mathrm{Pa}$. This method and its evaluation will be discussed in detail elsewhere. A brief description of the method involves adding $1 \mathrm{~mL}$ of $9 \mathrm{M}$ $\mathrm{H}_{2} \mathrm{SO}_{4}$ to the eluent (in a plastic beaker capable of heating to $130{ }^{\circ} \mathrm{C}$ ) and evaporating to a constant volume at $90{ }^{\circ} \mathrm{C}\left(\mathrm{H}_{2} \mathrm{SO}_{4}\right.$ does not evaporate at this temperature) and then following the previously described method with a $\mathrm{pH}$ of 2 , an electrodeposition time of 1.5 hours, at a constant current of 0.75 amps. 
Samples were then counted by alpha spectrometry for 100,000 seconds in the previously described system.

\section{Results and discussion}

\section{Alpha spectrometry of alpha emitting thorium isotopes}

The alpha spectrometric determination of isotopic thorium in biogogical samples has been reported in several publications. Both ${ }^{234} \mathrm{Th}$ and ${ }^{229} \mathrm{Th}$ have been used as radiochemical tracers. Alpha emitting ${ }^{229} \mathrm{Th}$ has a number of properties which make it superior to ${ }^{234} \mathrm{Th}$ for tracer recover including a $7340 \mathrm{y}$ half-life and availability as an SRM from NIST. Disadvantages of using ${ }^{229} \mathrm{Th}$, however, include recoil contamination of the detector with short-lived, alphaemitting progeny $\left({ }^{225} \mathrm{Ac}\right.$ and its daughters) which can interfere with ${ }^{228} \mathrm{Th}$ measurements at high activities. Also, low probability $(\sim 0.3 \%){ }^{229} \mathrm{Th}$ alpha emissions are present in the ${ }^{230} \mathrm{Th}$ region of interest which must be accounted for to preciude bias for low activity measurements. A cross-over value of $(5 \pm 1) \mathrm{x}$ $10^{-3}$ counts ${ }^{230} \mathrm{Th} /{ }^{229} \mathrm{Th}$ was experimentally determined for the reported method and has been used to correct the counts of ${ }^{230} \mathrm{Th}$.

Electrodeposited thorium sources must have good alpha spectrometric resolution $\left(<30 \mathrm{keV}\right.$ FWHM) because of the proximity of the ${ }^{229} \mathrm{Th}$ tracer alpha peaks to ${ }^{230} \mathrm{Th}$. The reliability of the measurement of ${ }^{230} \mathrm{Th}$ and ${ }^{232} \mathrm{Th}$ by alpha spectrometry was evaluated by measuring QC samples spiked over a range of activities. Excellent agreement between the measured value and the expected value was obtained for activities greater than the MDA of the method.

Figure 1 shows an alpha spectrum for a sample containing ${ }^{232} \mathrm{Th},{ }^{230} \mathrm{Th}$, ${ }^{228} \mathrm{Th}$ and isotopic tracer ${ }^{229} \mathrm{Th}$. The tracer allows for the conversion of the number of counts to activity because there is no change in detector efficiency over the energy range of interest. The number of counts in each region of interest is determined. The background spectum for each detector was previously obtained and the same region of interest used for each isotope in the sample used to determine the appropriate background. Figure 2 shows the results of the determination of various activities of ${ }^{232} \mathrm{Th}$ which clearly shows that the method is limited to approximately $10^{-3} \mathrm{~Bq}$, and $10^{-2} \mathrm{~Bq}$ for good precision measurements. 

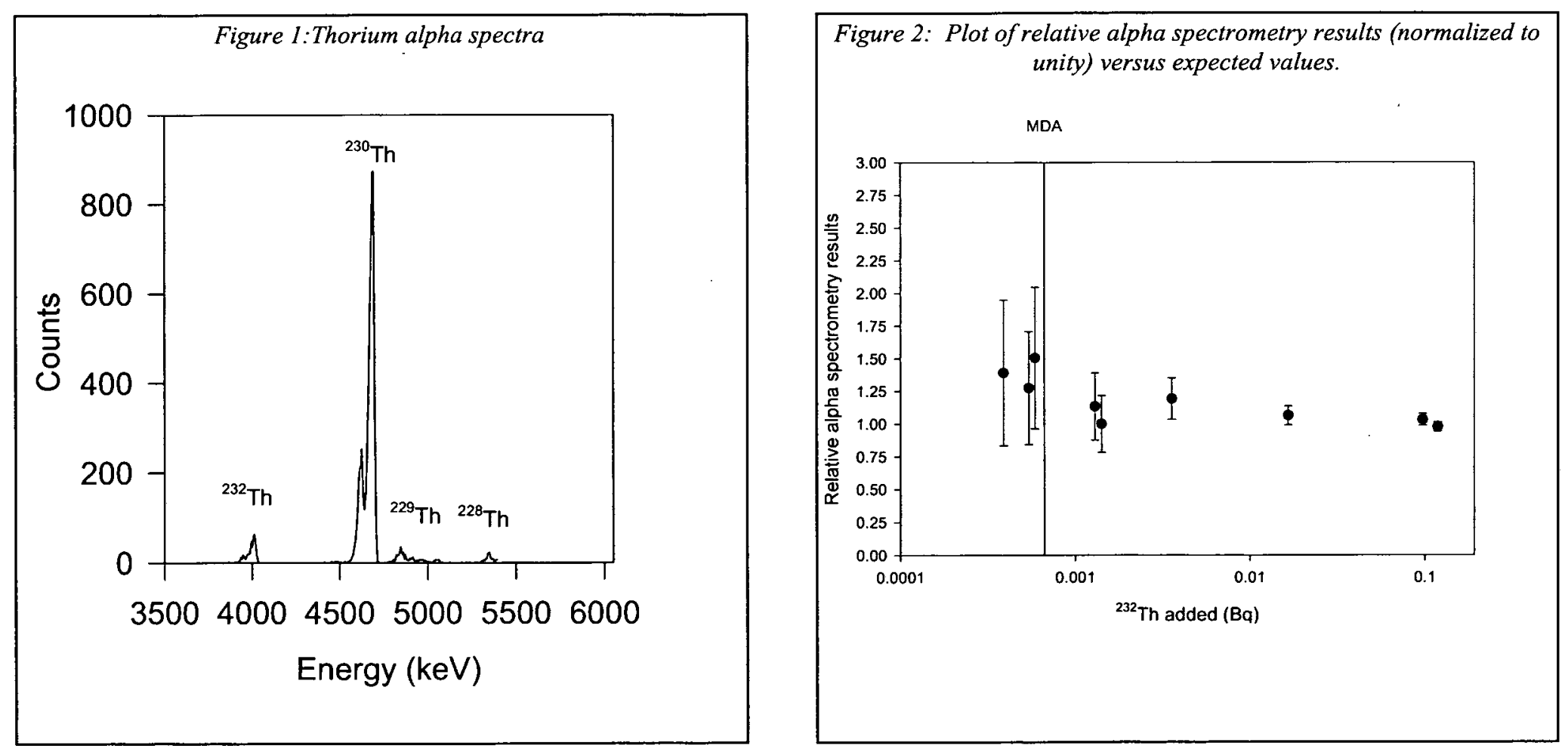


\section{Determination of ${ }^{232}$ Th by PCNAA and PCRNAA}

Selection of an appropriate substrate was critical to the success of this method. Typically stainless steel or platinum planchets are used for alpha spectrometry. Both are unsuitable for subsequent determination of ${ }^{232} \mathrm{Th}$ by NAA because of the large activity due to $(n, \gamma)$ reaction products (e.g. ${ }^{59} \mathrm{Fe},{ }^{31} \mathrm{Cr}$, ${ }^{191,197} \mathrm{Pt}$ ) which increases the background under the ${ }^{233} \mathrm{~Pa}$ gamma ray peaks. Neutron irradiation of vanadium planchets, however, produces predominantly ${ }^{52} \mathrm{~V}\left(\mathrm{t}_{1 / 2}=3.76 \mathrm{~min}\right)$ from the ${ }^{51} \mathrm{~V}(\mathrm{n}, y){ }^{52} \mathrm{~V}$ reaction plus small amounts of ${ }^{47} \mathrm{Sc}$ and ${ }^{48} \mathrm{Sc}$ from fast neutron $(\mathrm{n}, \alpha)$ reaction on ${ }^{50} \mathrm{~V}$ and ${ }^{51} \mathrm{~V}$, respectively. The radionuclides induced by the irradiation of the vanadium planchet did not interfere in the determination of ${ }^{233} \mathrm{~Pa}$ but do contribute to the background under the ${ }^{233} \mathrm{~Pa} \gamma$-rays and make it necessary to optimize counting conditions. The signal to noise ratio was optimized after 9-10 days decay.

The gamma ray spectrum of an irradiated vanadium planchet electroplated with ${ }^{232} \mathrm{Th}$ showing three main gamma ray emissions $(300,312,340 \mathrm{keV})$ from ${ }^{233} \mathrm{~Pa}$ is shown in Figure 3. The spectrum of a radiochemical blank carried through the method (tracer, separation, electrodeposition, alpha spectrometry, and neutron activation) is shown in Figure 3 was found to be free of peaks interfering with the determination of ${ }^{233} \mathrm{~Pa}$. Gamma-ray peaks resulting from impurities or nuclear reactions in the vanadium disk include the $320 \mathrm{keV}$ peak from ${ }^{51} \mathrm{Cr}$ and the very minor 308 and $316 \mathrm{keV}$ gamma ray peaks from ${ }^{182} \mathrm{Ta}$.

The precision and accuracy of the PCNAA determination of ${ }^{232} \mathrm{Th}$ was measured for a series of ${ }^{232} \mathrm{Th}$ quality control standards and the results are shown in Figure 4. The data demonstrate that the method generates accurate and precise results for ${ }^{232} \mathrm{Th}$ determination for activities well below those achievable by alpha spectrometry. The fixed geometry of the planchets allows for highly reproducible positioning of sources and standards. Figure 4 further shows that there is a small, but not negligible, blank.

PCNAA offers a very large increase in sensitivity for the determination of ${ }^{232} \mathrm{Th}$ compared to alpha spectrometry and this is evident from the improved detection limits and precision for low activity samples. A sensitivity enhancement of approximately 83,000 versus the alpha spectrometric determination of ${ }^{232} \mathrm{Th}$ was obtained.

The detection limit of ${ }^{232} \mathrm{Th}$ by this method varies with the count time of the sample. A detection limit in tissue samples of approximately $5 \times 10^{-6} \mathrm{~Bq} / \mathrm{sample}$ $\left(3 \times 10^{-4} \mathrm{dpm}\right)$ was obtained using the stated parameters, approximately $1 / 50$ th the detection limit of ${ }^{232} \mathrm{Th}$ by alpha spectrometry. Detection limits were calculated based on ANSI NI3.30 criteria. ${ }^{19}$ Unlike many methods, the PCNAA method can be used to analyze very large samples. The activity concentration 
limit $(\mathrm{Bq} / \mathrm{g})$ depends primarily on the amount of sample available for analysis because matrix interferences are removed before neutron activation. The overall detection limits (MDA) exhibited by the PCNAA alpha spectrometry method for isotopic thorium compare very well with other reported methods. 

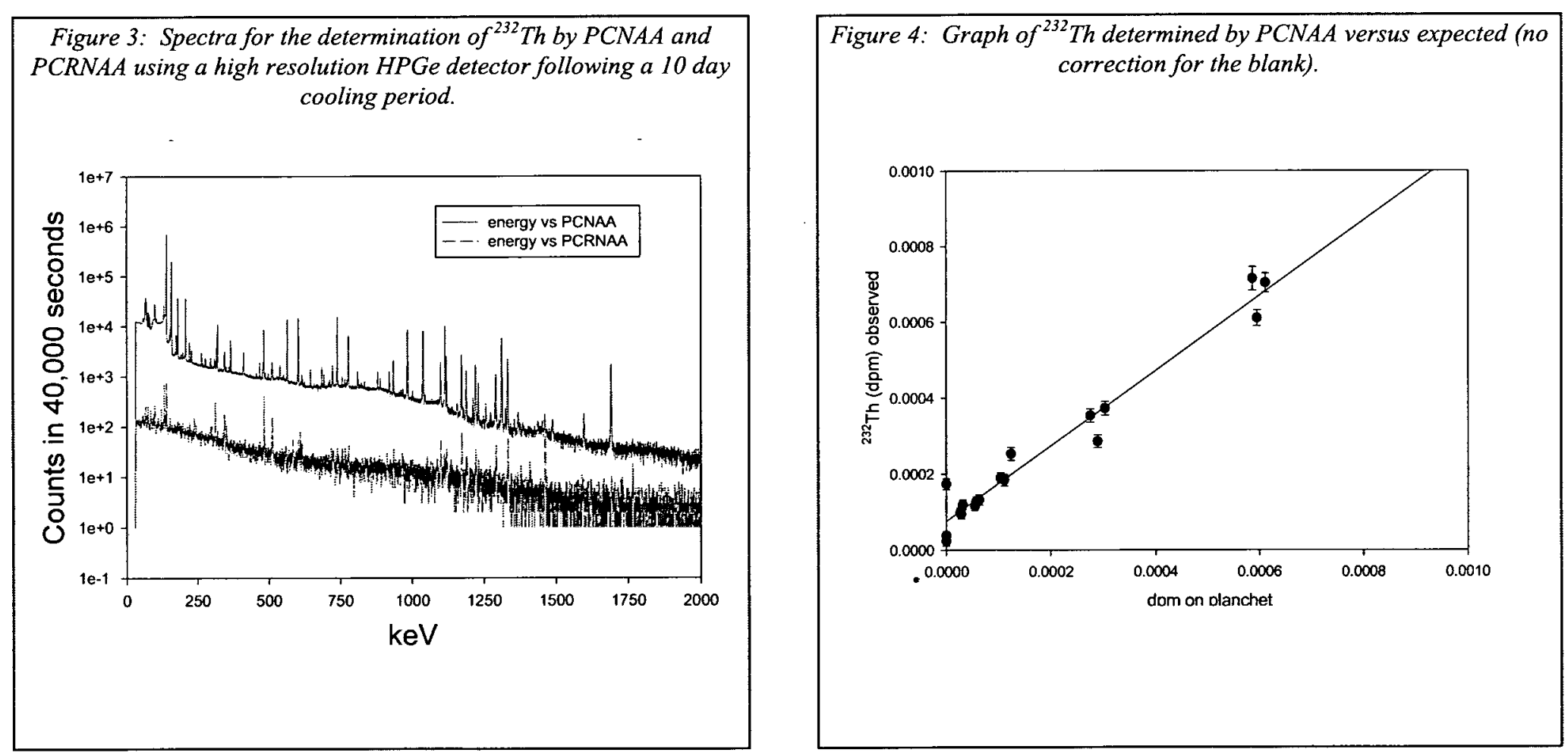


\section{Determination of ${ }^{232}$ Th PCRNAA}

Ion exchange chromatography was found to provide a very credible reduction in background interferences and consistently high recoveries $(95 \pm 5$ $\%$ ). Protactinium was found to be efficiently retained using the procedure previously described (Figure 5). Figure 6 shows an example of a sample counted after irradiation but prior to radiochemical separation of $\mathrm{Pa}$ for 80,000 seconds on a $48 \%$ HPGe detector in a low background shield containing $2 \mu \mathrm{Bq}$ of ${ }^{232} \mathrm{Th}$ with a higher than typical ${ }^{192} \mathrm{Ir}$ content (notice the 308 and $316 \mathrm{keV}$ peaks) which surround the $312 \mathrm{keV}$ peak used to determine the ${ }^{233} \mathrm{~Pa}$. Figure 6 further shows the results of this same sample following RNAA by ion exchange chromatography as previously described counted for the same time and duration. The ${ }^{192} \mathrm{Ir}$ content was reduced by factor of 30 for this example, and is typically much higher, in many cases with only trace levels of ${ }^{192}$ Ir remaining. Background for the $312 \mathrm{keV}$ region was reduced by a factor of 10-15 for the samples, resulting in a significant improvement in both the detection limit and the ability to determine ${ }^{232} \mathrm{Th}$ in the blank. The effective detection limit for the method using the conditions as stated is $3.5 \times 10^{-7} \mathrm{~Bq}$ for ${ }^{232} \mathrm{Th}$ and it is capable of $3-5 \%$ precision at levels above the limit of quantification. The method showed itself to provide reliable results for the determination of ${ }^{232} \mathrm{Th}$ (Figure 7).

Table 1: Comparison of mass and activity of important isotopes

\begin{tabular}{|c|c|c|c|}
\cline { 2 - 4 } \multicolumn{1}{c|}{} & \multicolumn{3}{c|}{ Detection limit (Bq) } \\
\cline { 2 - 4 } \multicolumn{1}{c|}{} & Alpha Spec & PCNAA & PCRNAA \\
\hline${ }^{228} \mathrm{Th}$ & $6 \times 10^{-4}$ & - & - \\
\hline${ }^{230} \mathrm{Th}$ & $2.8 \times 10^{-4}$ & - & - \\
\hline${ }^{232} \mathrm{Th}$ & $2.8 \times 10^{-4}$ & $5 \times 10^{-6}$ & $3.5 \times 10^{-7}$ \\
\hline
\end{tabular}



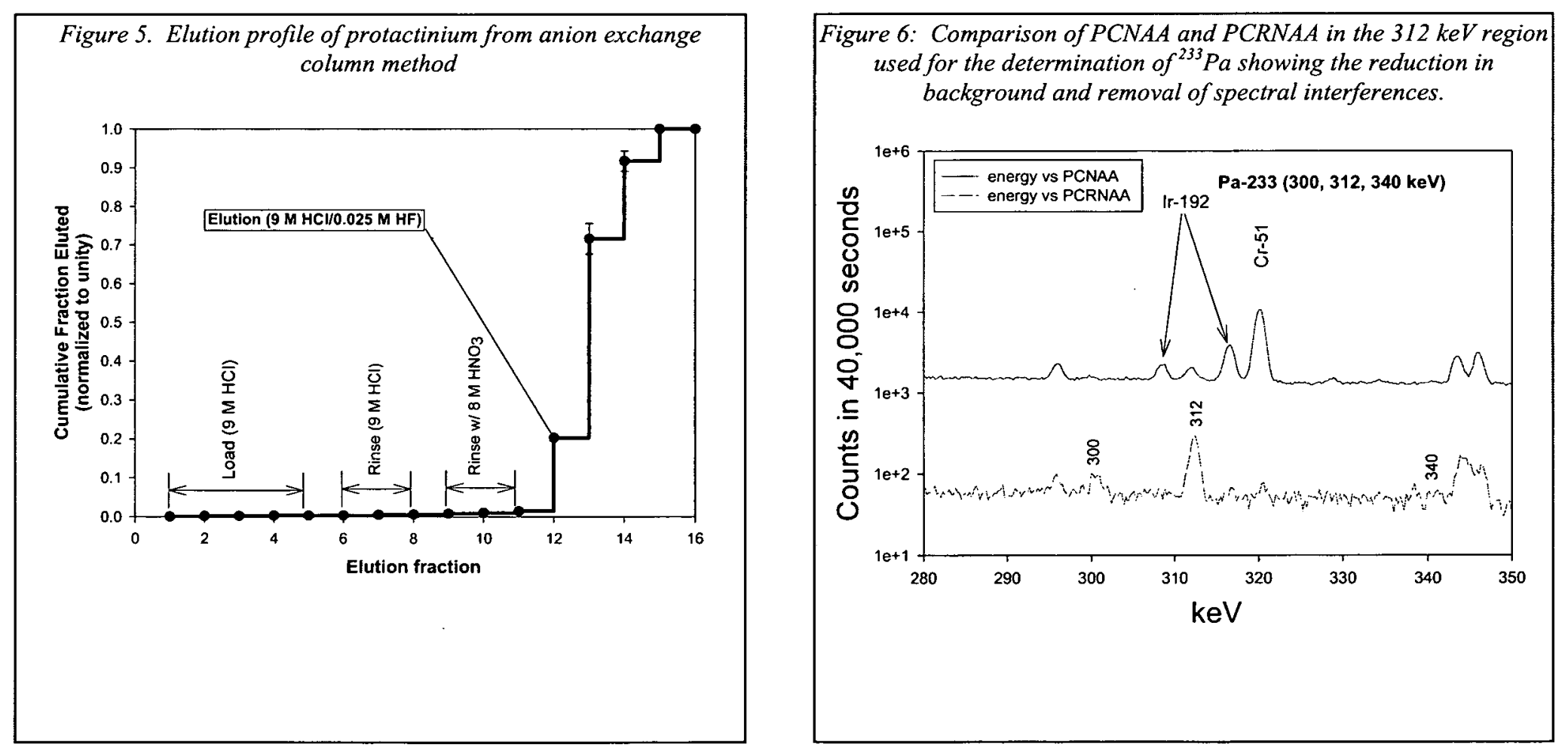


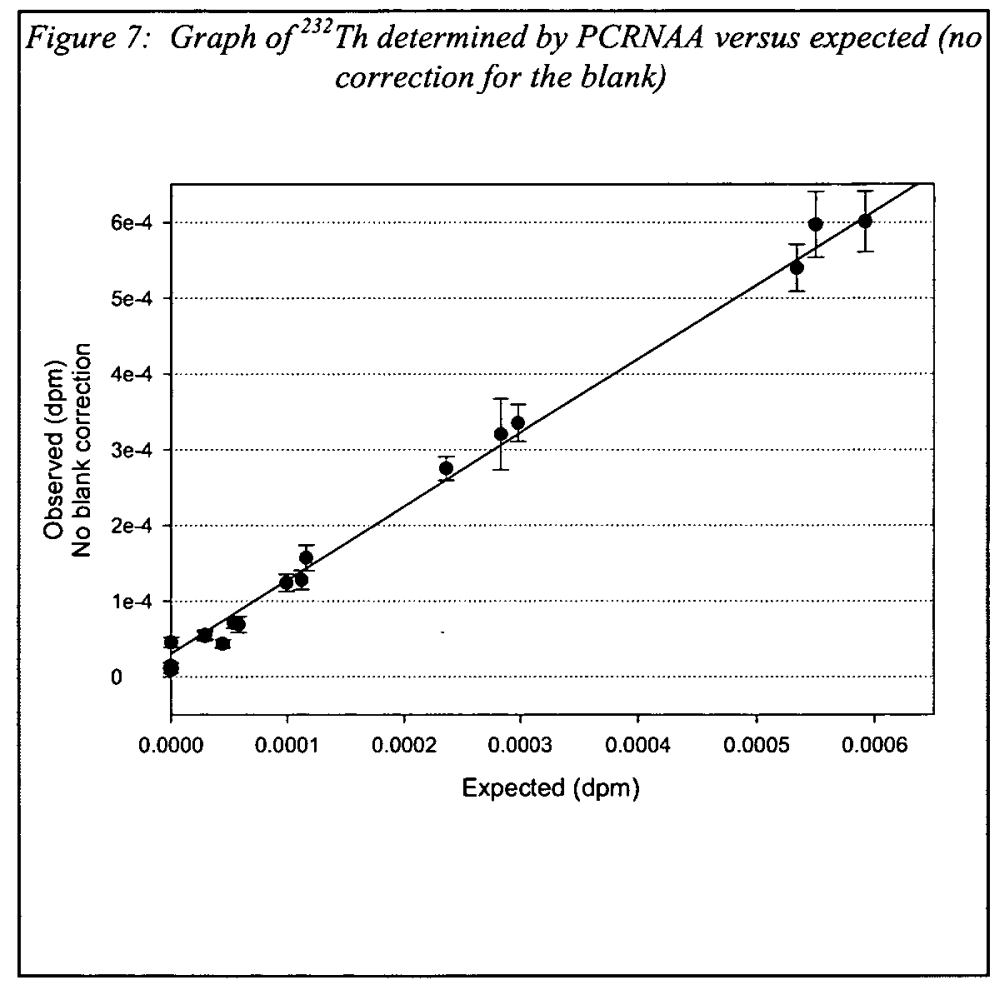




\section{References}

1. Wrenn, M.E.; Singh, N.P.; Cohen, N.; Ibrahim, S.A.; Saccomanno, G. NUREG/CR-1227 US Nuclear Regulatory Commission. Washington, D.C., 1981.

2. Environmental Measurements Laboratory Procedures Manual: HASL-300. 27th edition. U.S. Dept. of Energy, New York, 1992.

3. Kitamura, K.; Inazawa, Y.; Moritimo, T.; Sato, K; Higuchi, H.; Imai, K.; Watari, K.. J. Radioanal. Nuclear Chem 1997, 217, 175

4. Clifton, R.J.; Farrow, M.; Hamilton, E.L. Ann. Occ. Hyg. 1971, 14, 303.

5. Sunta, C.M.; Dang, H.S.; Jaiswal, D.D. J. Radioanal. Nuclear Chem. 1987, 1,149 .

6. Lucas, Jr., H.F.; Edgington, D.N.; Markun, F. Health Physics 1970, 19, 739.

7. Edgington, D.N. Int. J. Applied Rad. Isot. 1967, 18, 11.

8. Picer, M.; Strohal, P. Anal. Chim. Acta 1968, 40, 131.

9. Jaiswal, D.D.; Dang, H.S.; Sunta, C.M. J. Radioanal. Nuclear Chem 1985, $88 / 2,225$.

10. Glover, S.E., Filby, R.H., Clark, S.B. J. of Radioanal. Nuclear Chem. 1998, 234, 201.

11. Crain, J.S.; Smith, L.L.; Yaeger, J.S.; Alvarado, J.A. J. Radional. Nuclear Chem 1995, 194, 133.

12. Crain, J.S. Spectroscopy 1996, $11,31$.

13. Crain, J.S.; Mikesell, B.L.. Appl. Spectroscopy 1992, 46, 1498.

14. Terry, K.W.; Hewson, G.S.; Meuner, G. Health Physics 1995, 68, 105.

15. Table of Radioactive Isotopes. Browne, E.; Firestone, R.B.; Editor Shirley, V.S. John Wiley \& Sons, New York, 1986.

16. Walker, F.W.; Parrington, F.R.; Feiner; F. Nuclides and Isotopes. 14th edition. GE Nuclear, San Jose, CA. 1989.

17. McInroy, J.F.; Boyd, H.A.; Eutsler, B.C.; Romero, D. Health Physics $1985,49,587$.

18. Glover, S.E., Filby, R.H., Clark, S.B. J. of Radioanal. Nuclear Chem. 1998, 234, 213.

19. Performance Criteria for Radiobioassay; Standard N13.30. American National Standards Institute. 1996. 